\title{
ST segment changes as a surrogate end point in coronary thrombolysis
}

The role of thrombolysis in the treatment of acute myocardial infarction is now established by the GISSI study, which was presented at the time of the American College of Cardiology scientific sessions in New Orleans in March 1990. The enormous size and costs required to measure the difference in mortality in comparative trials impose many limitations and in future small specific subsets will need to be studied. There is increasing interest in examining surrogate end points for coronary artery patency in such studies.

The extent of the improvement in left ventricular function shown after reperfusion is disproportionately small compared with the associated reduction in mortality, suggesting that reperfusion has an as yet unidentified benefit. The patency of the infarct related vessel therefore remains the main goal of treatment and coronary arteriography remains the "gold standard" for the assessment of reperfusion. Identification of reperfusion is important in the assessment of the efficacy of new thrombolytic agents, differing regimens of administration of available agents (such as bolus dosing), or the role of adjunctive medication such as antiplatelet treatment. The identification of arteries that remain occluded is also important because it predicts a higher mortality in some patients, who might benefit from early additional intervention such as intracoronary thrombolysis or salvage angioplasty.

The complications associated with early angiography have been overestimated because they may include those of angioplasty with its additional risk of bleeding complications and coronary artery occlusion. Further assessment of the risk-benefit ratio of angiography in acute myocardial infarction is required, because the management of patients may be improved by the identification of the number of diseased vessels, the patency or occlusion of the infarct related artery, and early assessment of left ventricular function. A recent trial to compare the angiographically demonstrated patency rates achieved after the administration of either anistreplase or streptokinase focused attention on the ethical aspects of performing invasive procedures early after myocardial infarction in the presence of thrombolysis. ${ }^{12}$ We need to know more about the risks of local haemorrhage, bleeding at distant sites, and the morbidity associated with angiography.

\section{Non-invasive assessment of reperfusion}

Non-invasive markers associated with reperfusion have been tested to determine their specificity and sensitivity in predicting early vessel patency. Reperfusion may alter the temporal patterns of release of creatine kinase or its specific cardiac isoenzyme. Myoglobin or myosin release may show different temporal and qualitative patterns with reperfusion. Because these investigations are not immediately available in most coronary care units, such determinations tend to be retrospective, which limits their clinical usefulness for decisions made early in the course of myocardial infarction.
The measurement of the changes in the ST segment of the electrocardiogram therefore remains an attractive noninvasive investigation. It is widely used and understood and can be repeated with a high degree of reproducibility. Group studies showed that there is a greater fall in ST segment elevation in patients who reperfuse than in those who do not. We still do not know how useful this measurement is in predicting reperfusion in individual patients. The use of various methods to analyse the changes in ST segment - measurements from multiple dipole electrograms, the sum of ST segments over a 12 lead electrocardiogram, or serial assessment of individual leads showing significant ST elevation - has led to confusion. The assessment of the degree of ST segment change (expressed as a percentage fall or as a fractional change) that can be considered diagnostic, the timing of the reference electrocardiogram, and other clinical variables are also important. Clinical factors include the time from the onset of symptoms, the presence of previous myocardial infarction, and the influence of collateral vessels (which may affect myocardial perfusion if the culprit artery is occluded).

In our recent comparative study, the coronary artery patency achieved after anistreplase increased from $55 \%$ on first visualisation to $64 \%$ at the end of angiography performed 90 minutes after administration. This emphasises that the findings in the early period after thrombolysis are very variable and that the electrocardiographic criteria to indicate reperfusion will only be valid if applied to electrocardiograms recorded at the appropriate time. Previous studies suggested that a fractional change of $50 \%$ was highly specific and sensitive for determining coronary artery patency. ${ }^{3}$ This study was limited by the small number of patients who did not achieve reperfusion. Angiography was performed relatively late which may have led to a falsely high patency rate.

Saran et al (page 113) examined the specificity and sensitivity of a fractional change to $25 \%$ for predicting coronary artery patency; they also assessed its relation to left ventricular function. They used careful angiographic studies with TIMI grade classification and non-invasive and invasive assessments of left ventricular function. They did not study many patients, however, and the high degree of patency achieved by thrombolysis or by the addition of angioplasty meant that only eight of the series of 45 had non-patent arteries. In addition, three of the patients had well developed collateral vessels, and this may have influenced the subsequent improvement in the ST segment. None the less, the concept that failure to reduce the ST segment by $25 \%$ over 3 hours can predict non-reperfusion is an attractive one. Melandri et al (page 118) presumed that a reduction in ST segment elevation predicted reperfusion and they used the time to a reduction in fractional change of $50 \%$ to assess the results of two treatments - streptokinase alone and streptokinase with heparin. The electrocardiograms were taken at the same time as the measurements used to construct concentration 
curves for serum creatine kinase. This small study suggests that differences associated with different thrombolytic regimens can be identified.

The two studies in the current issue continue the debate on the usefulness of ST segment changes as surrogate end points for reperfusion. Coronary angiography remains the reference standard, and the ethics of performing early angiography need further discussion. We believe that angiography is justifiable if the patient can give informed consent and the issues are discussed with any accompanying relatives. Prospective studies are needed of patients who show no fall in ST segment elevation 3 hours after thrombolysis. Early angiography and intervention, either by intracoronary thrombolysis or angioplasty, need to be evaluated in this group. Further studies are also required of electrocardiographic and biochemical markers to improve the non-invasive identification of coronary artery reperfusion.
W STEWART HILLIS K J HOGG

University of Glasgow,

Department of Medicine and Therapeutics,

Western Infirmary,

Gardiner Institute,

Glasgow G11 6NT

1 Hogg KJ, Gemmill JD, Burns JMA, et al. Angiographic patency study of anistreplase versus streptokinase in acute myocardial infarction. Lancet 1990;335:254-8.

2 Anonymous. Surrogate measures in clinical trials. Lancet 1990;335:261-2.

3 Hogg KJ, Hornung RS, Howie CA, Hockings N, Dunn FG, Hillis WS. Electrocardiographic prediction of coronary artery patency after thrombolytic treatment in acute myocardial infarction; use of the ST segment as a non-invasive marker. Br Heart J 1988;60:275-80. 
been invoked as a cause of early recoarctation after surgical repair. It must be more likely after balloon dilatation when the ductal tissue is neither incised nor removed.

Whatever the mechanism of restenosis, it is an important problem which taken with the early failure rate makes balloon dilatation unattractive in this group of patients. Particularly because surgical repair has a low mortality, ${ }^{15}$ and when the subclavian flap technique was used there is a low incidence of recoarctation. ${ }^{16}$ Thus, even in the absence of longer term follow up in the present series, we consider that surgical repair remains the best treatment for most neonates presenting with coarctation of the aorta.

Balloon dilatation of coarctation of the aorta can be performed in most neonates with a good early result. It is, however, unsuccessful and potentially dangerous in patients with associated isthmal hypoplasia. Furthermore, early restenosis is common, even when complete relief of coarctation is obtained. Though the technique may be useful when there are severe associated abnormalities, it cannot be recommended for general application in neonates with coarctation of the aorta.

1 Kan JS, White RI, Mitchell SE, Farmlett EJ, Donahoo JS, Gardner TJ. Treatment of restenosis of coarctation by percutaneous transluminal angiography. Circulation 1983;68:1087-94.

2 Saul JP, Keane JF, Fellows KE, Lock JE. Balloon dilation angioplasty of postoperative aortic obstructions. $A m \mathrm{~J}$ Cardiol 1987;59:943-8.

3 Rao PS. Which aortic coarctations should we balloon dilate? Am Heart $J$ 1989;117:987-9.

4 Lababidi ZA, Daskalopoulos DA, Stoekle H. Transluminal balloon coarctation angioplasty: experience with 27 patients. Am J Cardiol 1984;54:1288-91.

5 Wren C, Peart I, Bain H, Hunter S. Balloon dilatation of unoperated aortic coarctation: immediate results and one year follow up. Br Heart $J$ 1987;58:369-73.

6 Morrow WR, Vick GW, Nihill MR, et al. Balloon dilation of unoperated coarctation of the aorta: short and interunoperated coarctation of the aorta: short and inter-

7 Lock JE, Bass JL, Amplatz K, Fuhrman BP, CastenedaZuniga W. Balloon dilatation angioplasty of aortic coarcta-

tions in infants and children. Circulation 1983;68:109-16. Finley JP, Beaulieu RG, Nanton MA, Roy DL. Balloon catheter dilatation of coarctation of the aorta in young
infants. Br Heart $J 1983 ; 50: 411-5$. infants. Br Heart $J$ 1983;50:411-5.

Attia IM, Lababidi ZA. Transumbilical balloon coarctation angioplasty. Am Heart J 1988;116:1623-4.

10 Rao PS, Najiar HN, Mardini MK, Solymar L, Thapar MK. Balloon angioplasty for coarctation of the aorta: immediate and long-term results. Am Heart J 1988;115:657-65.

11 Sos T, Sniderman KW, Rettek-Sos B, et al. Percutaneous transluminal dilatation of coarctation of thoracic aorta post mortem. Lancet 1979;iii:970-1.

$12 \mathrm{Krabill} \mathrm{KA,} \mathrm{Bass} \mathrm{JL,} \mathrm{Lucas} \mathrm{RV,} \mathrm{et} \mathrm{al.} \mathrm{Dissecting} \mathrm{transverse}$ aortic arch aneurysm after percutaneous transluminal balloon dilation angioplasty for an aortic coarctation. Pediatr Cardiol 1987;8:39-42.

13 Suarez de Lezo J, Fernandez R, Sancho M, et al. Percutaneous transluminal angioplasty for aortic isthmic coarctation in infancy. Am J Cardiol 1984;54:1 147-9.

14 Ho SY, Anderson RH. Coarctation, tubular hypoplasia, and the ductus arteriosus. Histological study of 35 specimens. the ductus arteriosus. Histol

15 Kopf GS, Hellenbrand W, Kleinman C, Lister G, Talner N, Laks H. Repair of aortic coarctation in the first three months of life: immediate and long-term results. $A n n$ Thorac Surg 1986;41:425-30.

16 Nair UR, Jones O, Walker DR. Surgical management of severe coarctation of the aorta in the first month of life. $J$ Thorac Cardiovasc Surg 1983;86:587-90.

\section{CORRECTION}

Editorial. ST segment changes as a surrogate end point in coronary thrombolysis $W$ Stewart Hillis, $K J$ Hogg (August issue: volume 64: pages 111-2)-The authors have asked us to point out that their address should have read: Department of Medicine and Therapeutics, University of Glasgow, Stobhill General Hospital, Balornock Road, Glasgow G21 3UW. 